RESEARCH AND PRACTICE

\title{
Addressing childhood obesity in Georgia: Past, present, and future
}

Debra L Kibbe, $\mathrm{MS}^{1}$, Emily Anne Vall, $\mathrm{PhD}^{2}$, Christine Green, $\mathrm{BBA}^{2}$, Brenda F. Fitzgerald, $\mathrm{MD}^{2}$, Karen J. Minyard, $\mathrm{PhD}$, $\mathrm{MSN}^{1}$ and Kelly Cornett, $\mathrm{MS}^{2}$

${ }^{1}$ Georgia Health Policy Center, Georgia State University, Atlanta, GA and ${ }^{2}$ Georgia Department of Public Health, Atlanta, GA

\begin{abstract}
Background: The Trust for America's Health ranks Georgia $17^{\text {th }}(16.5 \%)$ in the nation for childhood obesity prevalence among youth aged 10-17 years. Georgia has a long history of addressing childhood obesity at the state, regional, and local levels. This report outlines the historical efforts in childhood obesity in Georgia from the mid-1990's to the present, summarizes current childhood obesity prevention and management strategies, and provides childhood obesity-related data relevant to the current strategies.
\end{abstract}

Methods: Childhood obesity-related efforts in Georgia from 1996 to the present are documented, along with how these efforts led to the creation of Georgia Shape. The Georgia Shape Childhood Obesity Prevention Initiative, created by Governor Nathan Deal in 2012, established a statewide, 10-year plan of action to address childhood obesity. It convenes more than 125 governmental, philanthropic, academic and business community partners quarterly to work towards reducing the incidence of childhood obesity and overweight in Georgia. Evidence supporting the Georgia Shape objectives is described, along with current program and policy efforts that may allow achievement of its goal of having 69\% of Georgia's children in a healthy weight range by the year 2023.

Results: Georgia's obesity rate for low-income, 2- to 4-year old children has decreased. Over the 2013-2015 school years, there has been no increase in BMI at the population level among school age children and youth, and the percentage of boys and girls with increased aerobic capacity has improved. Future efforts should focus on middle and high school students; engaging and educating parents of young children; and state policies that support safe, daily physical activity and access to healthy, local food.

Conclusions: A long history of childhood obesity activities in Georgia has led to a strategic plan of action, with contributions from many stakeholders. These efforts aim to reduce the prevalence of childhood overweight and obesity in Georgia over 10 years.

Key words: childhood obesity, physical activity, nutrition, interventions, policies, statewide

\section{INTRODUCTION}

The state of Georgia has a long history of addressing childhood obesity at the state, regional, and local levels. Such efforts were initiated before the American Academy of Pediatrics released the first pediatric overweight recommendations in 1998 (Barlow \& Dietz, 1998). Nevertheless, Georgia continues to have high levels of obesity prevalence among children and youth. The state is ranked 17th in the nation for childhood obesity among youth aged 10-17 years (Levi, Segal, St. Laurent, \& Rayburn, 2014). In 2011, 13.2\% of 2- to 4-year-olds from low-income families (Ogden, Carroll, Kit, Flegal, 2014) and $16.5 \%$ of 10 - to 17 -year olds in Georgia were obese (National Survey of Children's Health, 2011/12).

This historical review of childhood obesity in Georgia identifies what we consider to be key activities that emerged during the past 20 years to build awareness about and take action to address obesity, physical inactivity and poor nutrition in children and youth. Challenges that have hampered progress on addressing childhood obesity prevalence and related behaviors are noted. Finally, establishment of the statewide childhood obesity initiative, Georgia Shape, is summarized along with activities that are in place to work toward a goal of having $69 \%$ of Georgia's children within a healthy weight range by the year 2023 .

\section{METHODS}

\section{A historical review}

Articles published through 2015 were identified through electronic searches using the ERIC, Google Scholar, and PubMed databases. Other relevant documents (e.g., state plans, reports, press releases, and research briefs) were found through Google and Yahoo searches. Search terms used were 'Georgia' and 'childhood obesity,' 'physical activity,' 'nutrition,' 'obesity prevention,' and 'obesity research.' Relevant observations and activities that led to the statewide Georgia Shape childhood obesity initiative, established in 2012, are summarized within the framework of a historical timeline. 


\section{The 1990's}

In 1996, to examine strategies to address childhood obesity, physical activity, and nutrition behaviors, the Atlanta Physical Activity and Nutrition (PAN) Initiative was formed through a collaboration between Emory University Rollins School of Public Health, the International Life Sciences Institute Center for Health Promotion (ILSI), and the Centers for Disease Control and Prevention (CDC) Foundation. This collaboration resulted in a journal article titled "Childhood Obesity: Future Directions and Research Priorities” (Hill \& Trowbridge, 1998), which noted that the threat of obesity was great and that more investment in childhood obesity research was required. The PAN collaboration also supported a health behavior intervention titled “Go Girls!” (Resnicow, Taylor, Baskin, McCarty, 2005; Resnicow, Yaroch, Davis, Wang, Carter, Slaughter, Coleman, \& Baranowskim, 2000; Resnicow, Lazarus, Davis, Lyn, London, 1999). This work in urban Atlanta targeted African American adolescent females, a population particularly affected by childhood obesity, and led to strategies to improve the diet and physical activity behaviors of this group.

Also in 1996, the Georgia Coalition for Nutrition Education (GCNE) was formed (Georgia Coalition for Physical Activity and Nutrition, 2011) to focus on increasing nutrition knowledge and behaviors among Georgians. GCNE transitioned into the Georgia Coalition for Physical Activity and Nutrition (GPAN) with a revised mission to improve the health of all Georgians by combating overweight, obesity, physical inactivity, and chronic disease. GPAN members and partner organizations advocated for state-level policies to improve childhood nutrition and physical activity. In 2001, the first step was accomplished when a legislative committee was established to explore physical activity and physical education (PE) in Georgia schools. The Joint Study Committee on Physical Activities in Schools was created by Senate Resolution 252 (Georgia General Assembly, 2001). The committee recommendations suggested action to address two barriers to achieving quality school-based physical activity: 1) having a PE Coordinator at the Georgia Department of Education and 2) returning PE to the Quality Core Curriculum as a required subject. This work would inform the drafting of the Student Health and Physical Education Act (S.H.A.P.E. Act) prior to the 2009 legislative session.

To support the recommendation for greater awareness and more research in childhood obesity (Hill \& Trowbridge, 1998), ILSI, CDC, Emory University, The Georgia Health Foundation, Inc., American Cancer Society, and other subject matter and academic experts hosted an international childhood obesity conference in Atlanta, Georgia in May 1999. The conference leaders examined barriers to action, current strategies and future research needs in school, health care and community settings (Trowbridge \& Kibbe, 2002). The recommendations for future research guided the intervention priorities that ILSI and Children's Healthcare of Atlanta embarked upon to improve childhood obesity prevention and management practices among healthcare professionals and to address obesity among preschool and school-age children (Passehl, McCarroll, Buechner, Gearring, Smith \& Trowbridge, 2004; Beno, Hinchman, Kibbe \& Trowbridge, 2005; Dunlop, Leroy, Trowbridge \& Kibbe, 2007; Dennison, Yin, Kibbe, Burns \& Trowbridge, 2008; Williams, Carter, Dennison \& Kibbe, 2009; Smith, Annesi, Walsh, Lennon \& Bell, 2010; Kibbe, Hackett, Hurley, McFarland, Schubert, Schultz \& Harris, 2011).

In 1999, a non-profit organization, Kids Health, Inc., was formed in Georgia to promote healthy eating and physical activity in schools by use of evidence-based guidelines established by the CDC. Kids Health, soon re-named "HealthMPowers" (Allensworth \& Kay, 2014), became a leader in creating a framework for in-school health promotion services, technical assistance, and training. Their expertise in health and PE training resulted in HealthMPowers being selected by the Georgia Department of Education to lead the fitness assessment training that was conducted statewide following passage of the 2009 S.H.A.P.E. Act.

\section{The 2000's}

In 2000, the Georgia Legislature created a barrier to addressing childhood obesity by passing House Bill 1187 (A Plus Education Reform Act, 2000). The bill revised the instruction time in the core academic subject areas and, in the revision, PE was removed from the required middle school curriculum in Georgia public schools. The State Board of Education revised the Comprehensive Health and Physical Education Program as follows: K-5 schools must provide a minimum of 90 contact hours of instruction at each grade level in health and physical education; and 6-12 grade schools are authorized to make available instruction in health and physical education (Georgia State Board of Education, 2011, para. 18 b,c) The lack of a requirement for $\mathrm{PE}$ contact hours for middle schools was, and continues to be, a concern for many of the groups dealing with childhood obesity.

Seeing the need for additional strategies and policies to address childhood obesity, the Philanthropic Collaborative for a Healthy Georgia ("Philanthropic Collaborative") launched a Childhood Obesity Initiative in January 2003 (Georgia Health Policy Center, 2003). Facilitated by the Georgia Health Policy Center (GHPC) at Georgia State University, the Philanthropic Collaborative is an informal group of Georgia-based foundations that seeks to learn more about health care issues affecting the citizens of this State. The Philanthropic Collaborative established a childhood obesity task force comprised of representatives from foundations, public health and school health. The task force organized a symposium and prepared four issue briefs to examine childhood obesity issues, gaps, strategies, successes and opportunities for action in Georgia. These symposium summary and issue briefs guided the investment priorities of Philanthropic Collaborative members in making childhood obesity-related grants as well as identifying data and research gaps related childhood obesity, physical activity, and nutrition for Georgia's children. 
In 2003, the Georgia Division of Public Health received a grant from the CDC to address obesity, nutrition, and physical activity statewide (Georgia Department of Human Services, August 2005). Stakeholders convened in work groups and regional meetings were held throughout Georgia over 12 months to gather information for a plan to address obesity, physical activity and nutrition. During the summer of 2004, in concert with the information-gathering process for the state plan, Policy Leadership for Active Youth (PLAY) was established. PLAY was a policy research initiative of the Georgia State University Institute of Public Health in partnership with the Georgia Center for Obesity and Related Disorders of the University of Georgia and the Medical College of Georgia (Lyn, 2015). PLAY identified evidence-based strategies to increase physical activity, decrease sedentary behavior, and prevent childhood overweight in Georgia. The PLAY team completed two projects to guide childhood obesity policies: a statewide evaluation of local school wellness policies and an analysis of the nutrition and physical activity policy and environments in Georgia childcare centers (Lyn, O’Meara, Hepburn, Potter, 2012; Lyn, Maalouf, Evers, Davis, Griffin, 2011).

In March of 2005, Governor Sonny Perdue, in partnership with the Georgia Department of Human Resources (GDHR), launched the Live Healthy Georgia Campaign, a statewide, science-based movement to improve the wellbeing of Georgians focusing on specific behaviors: Be Active, Get Checked, Be Smoke-Free, Eat Healthy and Be Positive (GDHR, 2005). This was the first social marketing and communications campaign in Georgia to build awareness about obesity; poor diet; and inactivity in children, youth, and adults. Shortly after the launch of Live Healthy Georgia in summer 2005, the 10-year statewide obesity plan was published titled, Georgia's Nutrition and Physical Activity Plan - To Prevent and Control Chronic Disease in Georgia, 2005-2015 (Georgia Department of Human Resources, 2005). This plan set forth goals and objectives in preschools, schools, worksites, faith settings, and communities.

Objectives within the school section of the state plan included goals to increase the number of students who walked and biked to school. In 2005, Georgia received its first Safe Routes to Schools (SRTS) funding of $\$ 1,000,000$ from the Federal Department of Transportation (Georgia Department of Transportation [GDOT], 2012) to support these objectives. From 2005 to 2009, GDOT received \$16.9 million to support SRTS strategies throughout the state (GDOT, 2012). For Georgia schools, this funding led to greater awareness, understanding, and capacity promoting and sustaining strategies to support physical activity before and after school.

In 2005-2006, the Philanthropic Collaborative identified a lack of population-level data on obesity prevalence and physical activity among Georgia's students as a barrier to achieving state-level policy and program support. This led the group to identify experts to plan and conduct the Georgia Youth Fitness Assessment Pilot Study (GYFA), one of the first efforts to measure aerobic capacity (a measure of cardiovascular fitness), body composition, muscular strength, muscular endurance, and flexibility among a large sample of fifth- and seventh-grade students throughout the state. The results showed that 52\% of Georgia students did not meet the standard for healthy aerobic fitness and that $30 \%$ were outside the recommended range for body mass index (BMI) (Powell, Roberts, Ross, Phillips, Ujamaa \& Zhou, 2006).

Concern about childhood obesity prevalence and poor fitness was growing among state leaders and, during the 2007 Georgia Legislative Session, a Senate Diabetes and Childhood Obesity Study Committee was created by Senate Resolution 537. Information from Georgia's state nutrition and physical activity plan, PLAY, and the GYFA guided the Committee's recommendations which included promoting the establishment of basic nutritional standards for school foods, increasing the availability of healthy snacks and beverages in school vending machines, increasing mandatory daily $\mathrm{PE}$ requirements for grades $\mathrm{K}-12$, and encouraging the General Assembly and the Department of Education to promote measurement and reporting of BMIs within the school system.

In 2008, the GHPC used the GYFA results and data on childhood physical activity, nutrition, and obesity from Georgia and other states to create the Georgia childhood obesity systems dynamics model. This computer-based model estimates the impact of childhood interventions on obesity prevalence over a 10-year window. With Georgia policy makers, their staff, and experts in the field, relevant interventions, or "levers," were selected. The criteria for determining the interventions were: 1) they occurred in systems for which policy makers controlled state budgets or funding (e.g. education, healthcare, and transportation); and 2) there was evidence the lever would affect childhood physical activity, nutrition behaviors, or weight. Leading up to the 2009 legislative session, this model, along with the policy briefs from PLAY, was used to educate legislators on childhood obesity, physical activity, and nutrition (Minyard, Ferencik, Phillips \& Soderquist, 2014).

During the time that the childhood obesity model was being developed, the American Heart Association, Voices for Georgia's Children, and other state advocacy organizations interested in the health of children drafted and obtained support for a bill that involved gathering annual data on the fitness of Georgia's children. The Student Health and Physical Education (S.H.A.P.E.) Act, passed in 2009, is outlined in the Official Code of Georgia Annotated § 20-2777 (Student Health and Physical Education Act, 2009). This landmark Act requires each local school district to conduct an annual fitness assessment for all students in grades 1-12 enrolled in classes taught by certified PE teachers. The Cooper Institute's Fitnessgram tool was selected by an expert committee to assess student fitness in Georgia (Plowman \& Meredith, 2013). To ensure proper monitoring and reporting, the law requires the State Board of Education to “...submit an annual report to the Governor, beginning October 1, 2012, and annually thereafter” 
(Student Health and Physical Education Act, section c, 2009).

Childhood obesity in Georgia received a great deal of media attention following passage of the S.H.A.P.E. Act in early 2009. On September 24, 2009, Georgia Public Broadcasting featured interviews with subject matter experts, parents, and caregivers in a program titled, "Georgia Weighs In: A Childhood Obesity Special” (Georgia Public Television, 2009). Further, Children's Healthcare of Atlanta (CHOA) established a wellness movement called Strong4Life. As part of Strong4Life, CHOA formulated a social marketing campaign to build parental awareness about childhood obesity. In 2011, they released a series of television and radio advertisements, billboards, and supported other media efforts that highlighted childhood obesity facts and statistics in Georgia (Children's Healthcare of Atlanta, 2011). The Governor's Office recognized the opportunity to bring together the Georgia S.H.A.P.E Partnership, a group of government, education, healthcare, and non-profit leaders to collaborate on the effort to implement annual fitness assessments statewide (Georgia Department of Education [GaDOE], 2010). These partners supported funding, training, data centralization, a reward/recognition program, and development of a sustainable plan for long-term results. CHOA provided leadership in coordinating public-private funding and in developing a communication strategy and implementation plans for the pilot and the statewide initiation of the process for fitness assessment (GaDOE, 2012, p. 3).

In 2012, Governor Nathan Deal identified childhood obesity as a critical concern for the future health of Georgia. The Georgia Shape Childhood Obesity Prevention Initiative was created and a statewide, 10-year plan of action to address childhood obesity in Georgia was drafted. Georgia Shape aims to encourage healthy behaviors and to promote individual health through coordinated statewide policy and system-level efforts by offering resources to educators, healthcare providers, families, and individuals (Georgia Shape Strategy Map, 2016). This ecological approach targets multiple influences on health and aims to create a supportive and coordinated environment for increasing physical activity and improving nutrition.

\section{Today and into the Future}

Georgia Shape is governed by the 16-member Governor's Advisory Council on Childhood Obesity (Members of the Governor's Advisory Council on Childhood Obesity, 2016). The Council includes government officials and academic, private, and public leaders. Georgia Shape's various strategies, programs, and initiatives are divided into five sub-groups: Data and Evaluation, Nutrition, Physical Activity, Marketing and Communications, and Healthcare. Each sub-group is comprised of council members and academic, community, and subject matter experts, with more than 130 professionals across the state participating (What is Georgia Shape, 2016). The collaborative support from high-level leaders has eliminated many barriers and allowed state agencies and other partners to work together towards common goals.
High-impact Georgia Shape initiatives include the following:

- Power Up for 30 is a statewide physical activity program for Georgia's elementary schools (Williams, Franks, Kay, Meyer, Cornett \& Mosier, in press).

- The Georgia Shape physical activity and nutrition grants program provides funding and technical assistance to schools (more than 90 to date) to start or enhance their wellness policies and related activities.

- The Governor's Shape Honor Roll program recognizes program for schools engaged in achieving specific best practices in school wellness.

- The Georgia Shape/Quality Rated Early Care Center program recognizes early care centers that adhere to the highest level of nutrition and physical activity best practices

- The Five Star, Baby Friendly Hospital Initiative recognizes birthing hospitals across the state that are working toward "Baby Friendly" status in support of breastfeeding best practices (Georgia 5-Star Hospital Initiative, 2016).

To reduce the incidence of childhood overweight and obesity, large-scale interventions must be implemented. At present, the Georgia Shape intervention reaching the most Georgians is Power Up for 30, a statewide program that trains educators to integrate 30 minutes of daily physical activity for students in addition to improving the quality of PE classes. This program aligns with the CDC's Coordinated School Physical Activity Program (Comprehensive School Physical Activity Program, 2016) and facilitates creation of a physical activity action plan that fits the needs of schools. Pilot data from 39 schools suggest that this program improves measures of student BMI and aerobic capacity (Braun, Kay, Metzler, Doyle, Franks, Bertram, \& Gazmararian, in press). As of January 2016, more than half (784) of the elementary schools in Georgia have pledged to participate in the program.

Georgia Shape supports nutrition-based efforts, including the Strong4Life School Cafeteria program (Palmer, Skorcz, Hardy, Welsh \& Keong, in press), which trains school nutrition staff to implement components of Cornell University's Smarter Lunchroom Movement (Smarter Lunchroom Movement, 2016) and to promote the Alliance of a Healthier Generation's Healthy Schools Program (Alliance for a Healthier Generation, 2016); the USDA Food and Nutrition Service's Healthier U.S. School Challenge; and the Georgia Farm to School program to expand the USDA Food and Nutrition Service Fresh Fruit and Vegetable Program (Fresh Fruit and Vegetable Program, 2016).

Over the next 10 years, Georgia Shape will work to increase the number of students in the Healthy Fitness Zone for BMI from $59 \%$ to $69 \%$. Other objectives set forth in the Georgia Shape strategic plan include reaching disparate populations with culturally competent programming, increasing the aerobic capacity of Georgia's youth, increasing the breastfeeding rates across Georgia, and increasing the 
number of early care centers that achieve high-quality nutrition and physical activity standards.

Smaller, more explicit strategies are planned to address obesity from birth through age 18 and to involve statewide, coordinated efforts with targeted communication strategies and multiple partnerships among other state government agencies, private foundations, healthcare providers, professional athletic teams, and private companies. The efforts focus on middle and high schools, communities with high rates of chronic disease, parents of young children and child care centers, government and policy agencies, businesses, hospitals, and medical practices.

\section{RESULTS}

Over the past 20 years, the collective investment of many partners and stakeholders has resulted in progress on childhood obesity prevalence and student health and fitness. Between 2008 and 2011, Georgia's obesity rate for lowincome, 2- to 4-year old children fell from $14.8 \%$ to $13.2 \%$ (Robert Wood Johnson Foundation, 2015). The annual health and fitness assessment conducted in Georgia now captures information on more than one million children. As shown by a comparison of 2013 to 2015 fitness assessment results for Georgia students in grades 4-12, BMI rates are leveling, with three years of data showing no increase in prevalence rates and increases in the percentage of girls and boys in the healthy zone for aerobic capacity of $2.1 \%$ and 0.5\%, respectively (GaDOE, 2015; GaDOE, 2013) (Table 1). The number of students assessed has remained consistent over years, as has school district engagement and participation. Over the last three years, 99\% of schools submitted fitness data and adhered to the mandate.

\section{DISCUSSION}

The initial results of this long-term investment in childhood obesity prevention and management are favorable. An August 2013 report from the CDC showed that Georgia was one of 18 states and one U.S. territory that experienced a decline in obesity rates among 2- to 4-year-olds from lowincome families between 2008 and 2011 (CDC, 2013). This decline in Georgia's obesity rate for toddlers was statistically significant (Robert Wood Johnson Foundation, 2015).

Over the last four years, fitness data for Georgia showed improvement in obesity and aerobic capacity measures at the population level (Table 1). Fitness assessment results for more than 1 million Georgia children are encouraging with more students in the Healthy Fitness Zone (the healthy range defined by FitnessGram), suggesting that the statewide interventions and programs in Georgia are creating positive changes. A limitation to the work in Georgia is that, at this time, there is no law requiring middle school PE and that only one semester of PE is required in four years of high school. Since the data are collected through PE classes, this limits the fitness data collected for these age groups. Further, there is an absence of regular PE classes in which various interventions are disseminated for younger populations.

Table 1. Percent of Students in the Healthy Fitness Zone (HFZ) on Georgia Fitness Assessment Results, 2012-2015

\begin{tabular}{|c|c|c|c|}
\hline $\begin{array}{c}\text { FitnessGram } \\
\text { Test Year }\end{array}$ & Students Tested & BMI: \% in HFZ, Grades & $\begin{array}{c}\text { Aerobic Capacity: } \% \text { in } \\
\text { HFZ, Grades 4-12 }\end{array}$ \\
\hline 2012 & $998,774(67 \%)$ & Boys: $58.0 \%$ & Boys: $58.0 \%$ \\
& & Girls: $58.5 \%$ & Girls: $43.0 \%$ \\
\hline 2013 & $1,139,998(76 \%)$ & Boys: $59.4 \%$ & Goys: $58.5 \%$ \\
& & Girls: $59.7 \%$ & B3.6\% \\
\hline 2014 & $1,082,721(71 \%)$ & Boys: $59.4 \%$ & Girls: $45.0 \%$ \\
\hline 2015 & $1,144,084(74 \%)$ & Girls: $59.7 \%$ & Boys: $59.0 \%$ \\
& & Boys: $60.3 \%$ & Girls: $45.7 \%$ \\
\hline
\end{tabular}

Another area on which Georgia should focus is the gender gap in aerobic capacity. Across the four years of statewide fitness assessment, females have scored lower than males. Future work is needed to identify how to engage, motivate, and encourage this population to be more physically active.

Much of the work in Georgia can be replicated in other states. To date, partners and stakeholders have met with representatives of 10 states to discuss and share past and present efforts relating to childhood obesity and the successes in Georgia. The common themes in each discussion are to engage stakeholders and leaders statewide; to identify state baseline measures; and to create systemspecific goals, objectives, and strategies to deal with childhood obesity and fitness.

\section{CONCLUSION}

Efforts to deal with childhood obesity in Georgia have led to a strategic plan of action that extends to the year 2023. Progress in addressing childhood obesity is slow and steady, but it is being accomplished due to a diverse set of stakeholders engaging in a statewide, coordinated effort which, along with creation of the Georgia Shape initiative, contributes to population-based health with regard to childhood obesity and aerobic capacity measures. Within 10-years, these collaborative efforts are expected to reduce the overall prevalence of childhood overweight and obesity in Georgia. These efforts and lessons learned are being shared and are being replicated in other states. 
Acknowledgement

This effort is supported by CDC Public Health Block Grant 3B01OT009013-16.

\section{References}

A Plus Education Reform Act. Official Code of Georgia § 15-11-15 (2000). Retrieved from

http://www.legis.ga.gov/Legislation/Archives/19992000/leg/sum/ hb1187.htm.

About Childhood Obesity. Alliance for a Healthier Generation (n.d.). Retrieved from https://www.healthiergeneration.org/.

Allensworth, D, Kay, C. HealthMPowers: About Us, Who We Are. (2014) Retrieved from http://healthmpowers.org/about-us-3-4/.

Alliance for a Healthier Generation (n.d). Retrieved from http://www.schools.healthiergeneration.org

Barlow, S, Dietz, W. Obesity evaluation and treatment: Expert Committee recommendations. The Maternal and Child Health Bureau, Health Resources and Services Administration and the Department of Health and Human Services. Pediatrics. 1998,102(3):E29.

Beno, L, Hinchman, J, Kibbe, D, Trowbridge, F. Design and implementation of training to improve management of pediatric overweight. J Contin Educ Health Prof, 2005, 25(4):248-58.

Braun, H, Kay, C, Metzler, M, Doyle, JA, Franks, P, Bertram, K, Gazmararian, J: The effect of a 1-year physical activity intervention program on school-related physical activity environment and opportunities and aerobic capacity. Public Health Reports, in press.

Centers for Disease Control and Prevention (U.S.). (August 2013). Morbidity and mortality weekly report: Vital signs: Obesity among low-income, preschool-aged children - United States, 2008-2011. Atlanta, GA: Centers for Disease Control and Prevention.

Children's Healthcare of Atlanta. Children's Healthcare of Atlanta Launches Provocative Awareness Campaign to Combat Childhood Obesity. Press Release. August 23, 2011. Retrieved from http://www.choa.org/Child-Wellness/In-theNews/ /media/CHOA/Documents/AboutChildrens/Newsroom/Media-Kits/Childrens-Obesity-LaunchPress-Release.ashx.

Comprehensive School Physical Activity Program (CSPAP) (n.d.). Centers for Disease Control and Prevention. Retrieved from http://www.cdc.gov/healthyschools/physicalactivity/cspap.h tm.

Dennison, D, Yin, Z, Kibbe, D, Burns, S, Trowbridge, F. Training health care professionals to manage overweight adolescents: experience in rural Georgia communities. J Rural Health, 2008, 24(1):55-9.

Dunlop, A, Leroy, Z, Trowbridge, F, Kibbe, D. Improving providers' assessment and management of childhood overweight: results of an intervention. Ambul Pediatr, 2007, 7(6):453-7.

Fresh Fruit and Vegetable Program (n.d.). United States Department of Agriculture Food and Nutrition Service. Retrieved from http://www.fns.usda.gov/ffvp/fresh-fruit-and-vegetableprogram.

Georgia 5-STAR Hospital Initiative (n.d.). Georgia Department of Public Health. Retrieved from https://dph.georgia.gov/georgia-5star.

Georgia Coalition for Physical Activity and Nutrition. Who is GPAN? (2011) Retrieved from http://g-pan.org/who-is-gpan.php.

Georgia Department of Education. Annual Fitness Assessment Program Report. 2012. Retrieved from http://www.gadoe.org/Curriculum-Instruction-and-Assessment/ Curriculum-and-Instruction/Documents/Georgia\%20Annual\% 20Fitness\%20 Assessment\%20Report\%202012.pdf.

Georgia Department of Education. Annual Fitness Assessment Program Report. 2013. Retrieved from https://www.gadoe.org/Curriculum-Instruction-andAssessment/Curriculum-and-
Instruction/Documents/HPE/Georgia\%20Annual\%20

Fitness\%20Assessment\%20Report \%202013.pdf.

Georgia Department of Education. Annual Fitness Assessment Program Report. 2015. Retrieved

from https://www.gadoe.org/Curriculum-Instruction-andAssessment/Curriculum-andInstruction/Documents/HPE/Georgia.

Georgia Department of Education. Governor launches the Georgia S.H.A.P.E partnership. Press Release. September 23, 2010. Retrieved from https://www.gadoe.org/External-Affairs-andPolicy/communications/Pages/PressReleaseDetails.aspx? PressView=Archive\&pid=68.

Georgia Department of Human Services. Georgia DHR launches new campaign: Live Healthy Georgia!. March 22, 2005. Press Release. Retrieved from https://dhs.georgia.gov/georgia-dhrlaunches-new-campaign-live-healthy-georgia.

Georgia Department of Human Services. State uses many strategies to fight obesity. August 26, 2005. Press Release. Retrieved from http://dhs.georgia.gov/state-uses-many-strategies-fightobesity.

Georgia Department of Human Resources, Division of Public Health. Georgia's Nutrition and Physical Activity Plan to Prevent and Control Obesity and Chronic Diseases in Georgia, July 2005. Publication Number: DPH05/048HW. Retrieved from dph.georgia.gov/sites/dph.georgia.gov/files/20052015\%20Nutrition andPhysicalActivityPlanFINAL.pdf.

Georgia Department of Transportation. Safe Routes to School. When did SRTS start? (2012) Retrieved from: http://www.saferoutesga.org/content/when-did-srts-start.

Georgia General Assembly Senate Research Office. Report of the Joint Study Committee on Physical Activity in Georgia Schools. 2001. Retrieved from http://www.senate.ga.gov/sro/Documents/StudyCommRpts/01JtP hysicalActivityRpt.pdf.

Georgia Health Policy Center, Andrew Young School of Policy Studies, Georgia State University. Update: The Philanthropic Collaborative for a Healthy Georgia.

Retrieved from http://ghpc.gsu.edu/files/2014/01/PC_ChildhoodO besity.pdf.

Georgia Public Television. Georgia Weighs In: A Childhood Obesity Special. Sept 24, 2009. Retrieved from http://www.gpb.org/georgia-weighs-in-tv.

Georgia Shape Strategy Map (n.d.). Retrieved from http://www.georgiashape.org/

Georgia State Board of Education. Comprehensive health and physical education program plan. Rule number 160-4-2-.12 (2011). Retrieved from https://www.gadoe.org/External-Affairsand-Policy/State-Board-of-Education/SBOE\%20Rules/160-4-2.12.pdf.

Georgia Student Health And Physical Education (S.H.A.P.E.) Act, Official Code of Georgia Annotated § 20-2-777 (2009).

Hill, J, Trowbridge F. Childhood obesity: Future directions and research needs. Pediatrics, 1998, 101(3 Pt 2):570-4.

Kibbe, D, Hackett, J, Hurley, M, McFarland, A, Schubert, K, Schultz, A, Harris, S. Ten years of TAKE 10!(®): Integrating physical activity with academic concepts in elementary school classrooms. Prev Med, 2011, 1;52 Suppl 1:S43-50.

Levi, J, Segal, L, St. Laurent, R, Rayburn, J. The State of Obesity: Better Policies for a Healthier America, Trust for America's Health, September 2014. Retrieved from http://www.stateofobesity.org/.

Lyn, R. Policy Leadership for Active Youth (PLAY). (2015). Retrieved from http://publichealth.gsu.edu/research-2/policyleadership-for-active-youth/.

Lyn, R, Maalouf, J, Evers, S, Davis, J, Griffin, M. Nutrition and physical activity in child care centers: the impact of a wellness policy initiative on environment and policy assessment and observation outcomes, 2011. Prev Chronic Dis, 2013, 23(10):E83. 
Lyn, R, O'Meara, S, Hepburn, V, Potter, A. Statewide evaluation of local wellness policies in Georgia: An examination of policy compliance, policy strength, and associated factors. J Nutr Educ Behav, 2012, 44(6), 513-520.

Members of the Governor's Advisory Council on Childhood Obesity (n.d.). Retrieved from http://www.georgiashape.org/.

Minyard, K, Ferencik, R, Phillips, M, Soderquist, C. Using systems thinking in state health policymaking: an educational initiative. Health Syst (Basingstoke), 2014, 3(2):117-123.

National Survey of Children's Health. NSCH 2011/12. Data query from the Child and Adolescent Health Measurement Initiative, Data Resource Center for Child and Adolescent Health website. Retrieved 01/02/2016 from www.childhealthdata.org.

Ogden, C, Carroll, M, Kit, B, Flegal, K. Prevalence of childhood and adult obesity in the United States, 2011-2012. JAMA, 2014, 311(8): 806-814.

Palmer, W, Skorcz, A, Hardy, T, Welsh, J, Keong F: Strong4Life school nutrition program. Public Health Reports, in press.

Passehl, B, McCarroll, C, Buechner, J, Gearring, C, Smith, A, Trowbridge, F. Preventing childhood obesity: establishing healthy lifestyle habits in the preschool years. J Pediatr Health Care, 2004, 18(6):315-9.

Plowman, S, Meredith, M (eds.). Fitnessgram/Activitygram Reference Guide (4th Edition). Dallas, TX; 2013. The Cooper Institute.

Powell, K, Roberts, A, Ross, J, Phillips, M, Ujamaa, D, Zhou, M. Low physical fitness among fifth- and seventh-grade students, Georgia, 2006. Am J Prev Med, 2009, 36(4):304-10.

Power Up for 30 Success in Georgia (n.d.). Retrieved from http://www.georgiashape.org/.

Resnicow, K, Taylor, R, Baskin, M, McCarty, F. Results of go girls: a weight control program for overweight African-American adolescent females. Obes Res, 2005, 13(10):1739-48.

Resnicow, K, Yaroch, A, Davis, A, Wang, D, Carter, S, Slaughter, L, Coleman, D, Baranowski, T. GO GIRLS!: results from a nutrition and physical activity program for low-income, overweight African American adolescent females. Health Educ Behav, 2000, 27(5):616-31.
Resnicow, K, Lazarus, A, Davis, A, Lyn, R, London, Kotler, J. Go Girls!: Development of a Community-Based Nutrition and Physical Activity Program for Overweight African American Adolescent Females. J Nutrition Educ, 1999, 31:283C.

Robert Wood Johnson Foundation. Declining childhood obesity rates: Where are we seeing signs of progress? (2015, January). Retrieved

from http://www.rwjf.org/content/dam/farm/reports/reports/2015/ rwjf417749.

Smarter Lunchrooms Movement (n.d.). Retrieved from http://smarterlunchrooms.org/.

Smith, A, Annesi, JJ, Walsh, AM, Lennon, V, Bell, RA. Association of changes in self-efficacy, voluntary physical activity, and risk factors for type 2 diabetes in a behavioral treatment for obese preadolescents: a pilot study. J Pediatr Nurs, 2010, 25(5):393-9.

Trowbridge, F, Kibbe, D. Childhood Obesity: Partnerships for Research and Prevention. An ILSI Center for Health Promotion Monograph. 2002. ILSI Press. Retrieved 12/28/2015 from http://www.ilsi.org/ResearchFoundation/Publications/chpob esitymonograph.pdf.

What is Georgia Shape (n.d.). Retrieved from http://www.georgiashape.org/

Williams, C, Carter, B, Dennison, D, Kibbe, D. Increasing physical activity in preschool: A pilot study to evaluate Animal Trackers. J Nutr Educ Behav, 2009, 41(1):47-52.

Williams, S, Franks, P, Kay, C, Meyer, A, Cornett, K, Mosier, B: Bridging public health and education: Power up for 30 formative evaluation results. Public Health Reports, in press. 